The Journal of Bone E Joint Surgery
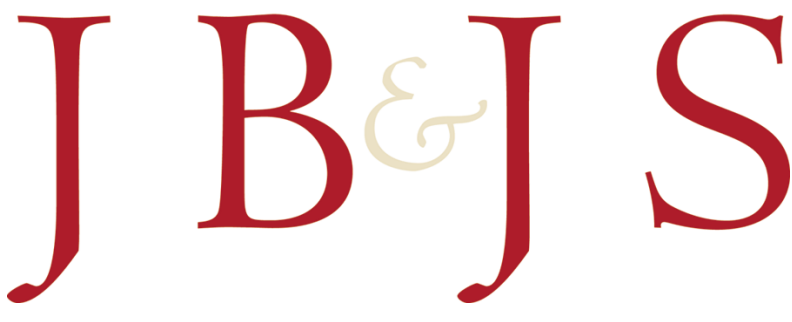

This is an enhanced PDF from The Journal of Bone and Joint Surgery

The PDF of the article you requested follows this cover page.

\title{
Modified Bilhaut-Cloquet Procedure for Wassel Type-II and III Polydactyly of the Thumb
}

Goo Hyun Baek, Hyun Sik Gong, Moon Sang Chung, Joo Han Oh, Young Ho Lee and Sang Ki Lee J Bone Joint Surg Am. 2007;89:534-541. doi:10.2106/JBJS.F.00812

This information is current as of September 4, 2009

Supplementary material

Reprints and Permissions

Publisher Information
Commentary and Perspective, data tables, additional images, video clips and/or translated abstracts are available for this article. This information can be accessed at http://www.ejbjs.org/cgi/content/full/89/3/534/DC1

Click here to order reprints or request permission to use material from this article, or locate the article citation on jbjs.org and click on the [Reprints and Permissions] link.

The Journal of Bone and Joint Surgery

20 Pickering Street, Needham, MA 02492-3157

www.jbjs.org 


\title{
Modified Bilhaut-Cloquet Procedure for Wassel Type-II and III Polydactyly of the Thumb
}

\author{
By Goo Hyun Baek, MD, Hyun Sik Gong, MD, Moon Sang Chung, MD, \\ Joo Han Oh, MD, Young Ho Lee, MD, and Sang Ki Lee, MD \\ Investigation performed at the Department of Orthopedic Surgery, Seoul National University College of Medicine, Seoul, South Korea
}

\begin{abstract}
Background: The Bilhaut-Cloquet operation is a combined surgical procedure for the treatment of a symmetric bifid thumb. Although this procedure can obtain a normal-sized thumb with a stable interphalangeal joint, it has limitations, such as the technical difficulty of combining all segments of a duplicated thumb, possible later physeal growth arrest, joint stiffness, and nail-plate deformity. We reviewed the results of our modification of this procedure for the treatment of Wassel type-II and III polydactyly of the thumb.
\end{abstract}

Methods: Seven patients, two with type-II and five with type-III polydactyly of the thumb, underwent the modified Bilhaut-Cloquet procedure and were followed for an average of fifty-two months. Cosmetic and functional assessments were made.

Results: All patients and their parents were satisfied with the cosmetic and functional results. Compared with the preoperative motion, the postoperative range of motion of the interphalangeal joint was preserved in thumbs with type-III deformity and was increased in those with type-II deformity. No nail deformity or growth arrest occurred, and remodeling and hypertrophy of the distal phalanx occurred with time.

Conclusions: Our modification of the Bilhaut-Cloquet procedure for the treatment of type-II and III thumb polydactyly is effective in preserving interphalangeal joint motion, minimizing nail deformity, and preventing growth arrest.

Level of Evidence: Therapeutic Level IV. See Instructions to Authors for a complete description of levels of evidence.

$\mathrm{R}$ adial polydactyly is a relatively common congenital anomaly that frequently presents as thumb duplication. In the treatment of thumb polydactyly, the simple ablation of one digit has not produced satisfactory results, and doing so frequently results in retained deviation or ligamentous instability of the thumb $\mathrm{b}^{1-5}$. Therefore, modern reconstructive strategies involving the combining of elements from both thumbs are indicated to achieve a functionally and cosmetically acceptable result ${ }^{6}$.

In 1969, Wassel developed a classification system for different types of thumb duplications on the basis of the level of bifurcation ${ }^{1}$. The Bilhaut-Cloquet procedure, which has been advocated for Wassel type-I or II thumbs with a bifid distal phalanx, consists of the coaptation of equal parts of bone, soft tissue, and nail tissue by resecting the central duplicated thumb segment ${ }^{7}$. With use of this method, correction of the circumference is relatively straightforward, resulting in a distal phalanx of at least normal size and usually with a sta- ble interphalangeal joint ${ }^{5}$. However, the results of the BilhautCloquet procedure are unpredictable because it is technically demanding to combine elements of both thumbs, including segments of bone, nail fold, nail bed, and the articular surface. Moreover, the reconstructed thumb often later develops complications of physeal growth disturbance, joint stiffness, and a nail-plate deformity or groove $e^{2,3,8,9}$.

We reviewed the results of a modified technique of the Bilhaut-Cloquet procedure for type-II and III polydactyly of the thumb, which was devised to resolve the above problems.

\section{Materials and Methods}

B etween 1997 and 2003, we reconstructed seven hands in B seven patients using a modified Bilhaut-Cloquet procedure. The inclusion criterion was Wassel type-II and III polydactyly, in which the bifid thumbs are symmetric and the nail size is less than two-thirds of that of the normal contralateral thumb, or smaller than the index fingernail in patients with

Disclosure: The authors did not receive any outside funding or grants in support of their research for or preparation of this work. Neither they nor a member of their immediate families received payments or other benefits or a commitment or agreement to provide such benefits from a commercial entity. No commercial entity paid or directed, or agreed to pay or direct, any benefits to any research fund, foundation, division, center, clinical practice, or other charitable or nonprofit organization with which the authors, or a member of their immediate families, are affiliated or associated. 
The JOURnAl of BOnE \& JOINT SURGERY • JBIS. ORG Volume 89-A · Number 3 - MARCH 2007
Modified Bilhaut-Cloquet Procedure for Wassel Type-II AND III POLYdaCtyly of The Thumb bilateral involvement. The parents of all patients gave informed consent prior to surgery. We retrospectively reviewed the results in seven consecutive patients after institutional review board approval.

\section{Surgical Technique}

The modified Bilhaut-Cloquet procedure differs from the originally described method because it is an extra-articular procedure; the interphalangeal joint is reconstructed with one thumb, and the other thumb contributes only part of the distal phalanx for stability. Because it is not necessary to approximate the articular surface of the distal phalanx, the nail bed can be sutured more precisely according to the natural curve of the nail to minimize nail plate deformity (Fig. 1).

Under tourniquet control, both nails are removed and a longitudinal incision is made through the nail bed of both thumbs in a manner by which the combined nail will best resemble a normal thumb. The incision is extended by a zigzag line proximally to the bifurcation level. The thumb with a greater range of interphalangeal joint motion is chosen to become the main articulating digit, as it contains the articular surface, the physis, and a major part of the distal phalangeal bone with the overlying nail bed. The other thumb, with lesser interphalangeal joint motion, is made into a fillet flap containing a minor part of the distal phalangeal bone supporting the incised nail bed and the collateral ligament attached to the proximal phalanx. The two distal phalangeal bones do not need to match exactly or to have intimate contact, but they are approximated and secured with one or two transverse Kirschner wires to make the combined nail bed look natural. To make one smooth semicircular nail bed in the axial plane, slight axial rotation is required because attaching two semicircular nails in a transverse plane alone creates a so-called seagull deformity (Fig. 2). Then the nail bed is repaired with buried 8-0 nylon sutures under slight tension. On the basis of our experience, this tension suture can prevent the formation of a prominent nail ridge, which often occurs after suture repair of the nail bed with absorbable sutures.

Joint stability is then tested, and, if required, an additional transarticular Kirschner wire can be driven from the tip of the thumb across the interphalangeal joint to stabilize it. One of the removed nails is then placed on the new nail bed, and a stabilizing suture is placed at each side of the nail. Alternatively, an artificial nail of normal size can be inserted to facilitate remodeling of the nail bed. A short or long-arm thumb-spica cast is applied, depending on the age of the patient, with a long-arm cast used in children under five years of age. The cast and the Kirschner wires are removed four to six weeks after surgery.

In a type-III deformity, the extra thumb is osteotomized at the bifurcation level and excised except for the distal bone fragment supporting the nail bed and the fillet flap. When the angular deformity of the interphalangeal joint is $>20^{\circ}$, a cor-

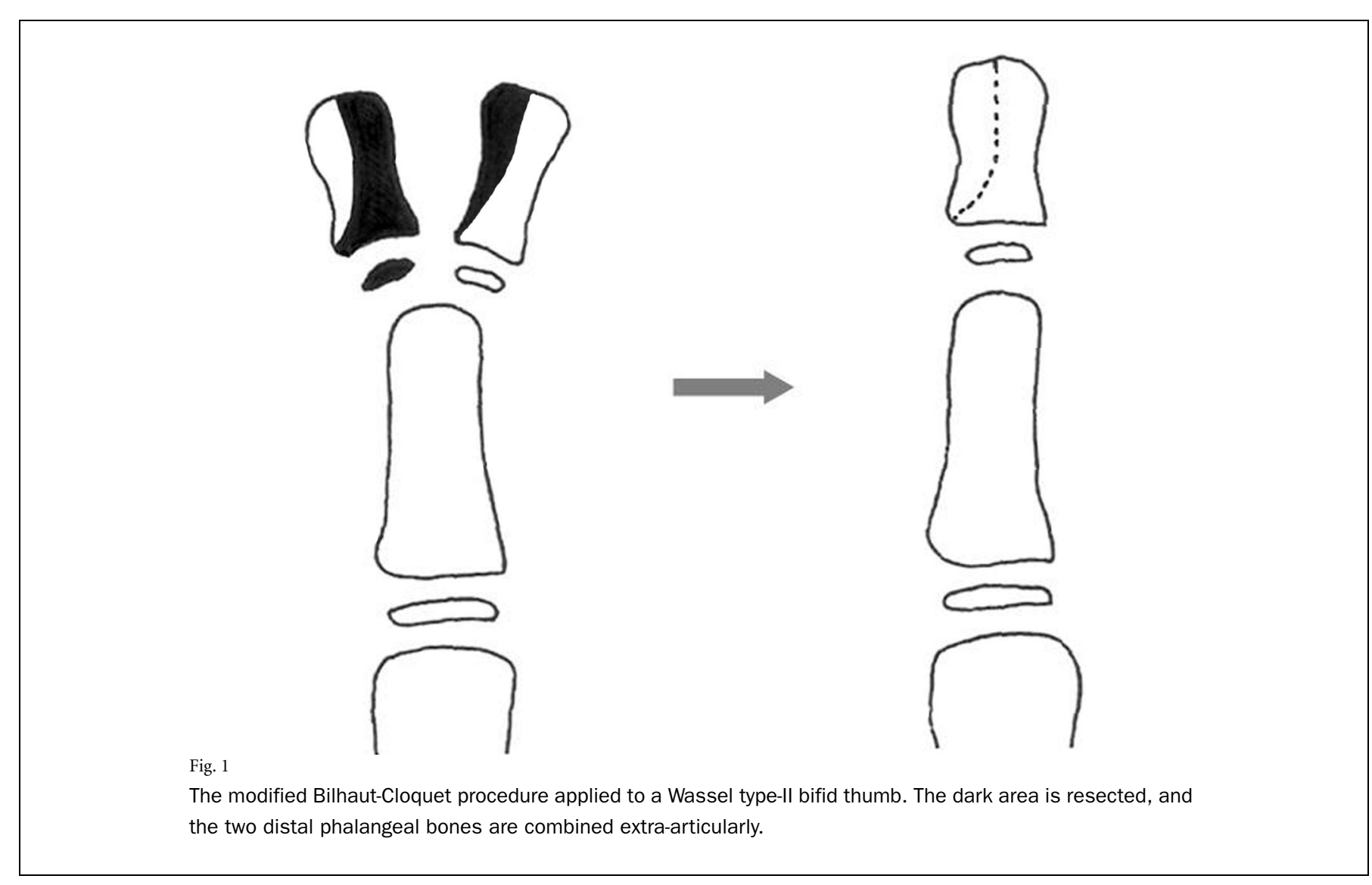


The Journal of Bone \& JoInt Surgery · JBJS.org VOLUme 89-A · Number 3 - MARCH 2007
Modified Bilhaut-Cloquet Procedure for Wassel Type-II AND III POLYDACTYLY OF THE THUMB

TABLE I Demographic and Clinical Data Before and After the Modified Bilhaut-Cloquet Procedure

\begin{tabular}{|c|c|c|c|c|c|c|c|}
\hline \multirow[b]{3}{*}{ Case } & \multirow{3}{*}{$\begin{array}{l}\text { Sex, Age } \\
\text { (mo) }\end{array}$} & \multirow[b]{3}{*}{ Side } & \multirow{3}{*}{$\begin{array}{c}\text { Type of } \\
\text { Polydactyly }\end{array}$} & \multirow{3}{*}{$\begin{array}{l}\text { Follow-up } \\
\text { Period (mo) }\end{array}$} & \multicolumn{3}{|c|}{ Range of Motion of Thumb* (deg) } \\
\hline & & & & & \multicolumn{2}{|c|}{ Preop. } & \multirow[b]{2}{*}{ Postop. } \\
\hline & & & & & Radial Digit & Ulnar Digit & \\
\hline 2 & M, 11 & $\mathrm{R}$ & III & 44 & $0 / 90$ & $0 / 90$ & $0 / 90$ \\
\hline 3 & M, 7 & $\mathrm{R}$ & III & 68 & $0 / 45$ & $0 / 45$ & $0 / 40$ \\
\hline 5 & M, 66 & L & III & 36 & $0 / 70$ & $0 / 60$ & $10 / 60$ \\
\hline 6 & M, 49 & L & II & 70 & $20 / 40$ & $20 / 40$ & $15 / 60$ \\
\hline 7 & M, 16 & $\mathrm{R}$ & II & 65 & $10 / 50$ & $10 / 50$ & $0 / 60$ \\
\hline
\end{tabular}

rective closing-wedge osteotomy is performed at the proximal phalanx of the retained thumb, and the osteotomy is held by advancing the transarticular Kirschner wire (Fig. 3).

\section{Patients and Evaluations}

There were seven patients, five boys and two girls. The mean age at the time of the surgery was thirty months (range, seven to sixty-six months). Two patients had a type-II deformity, and five had a type-III deformity. The five patients with a type-III deformity had a near normal range of motion of the interphalangeal joint preoperatively (average, $60^{\circ}$; range, $45^{\circ}$ to $90^{\circ}$ ); however, the two patients with a type-II deformity had marked limitation of joint motion in both rays, averaging $30^{\circ}$ (range, $20^{\circ}$ to $40^{\circ}$ ). All patients had a unilateral symmetric bifid thumb with a nail size that was less than two-thirds of that of the contralateral thumb. A closing-wedge osteotomy of the proximal phalanx was performed in two patients with a type-III deformity, as there was $>20^{\circ}$ of angulation at the interphalangeal joint level in both. All procedures were performed by one surgeon.
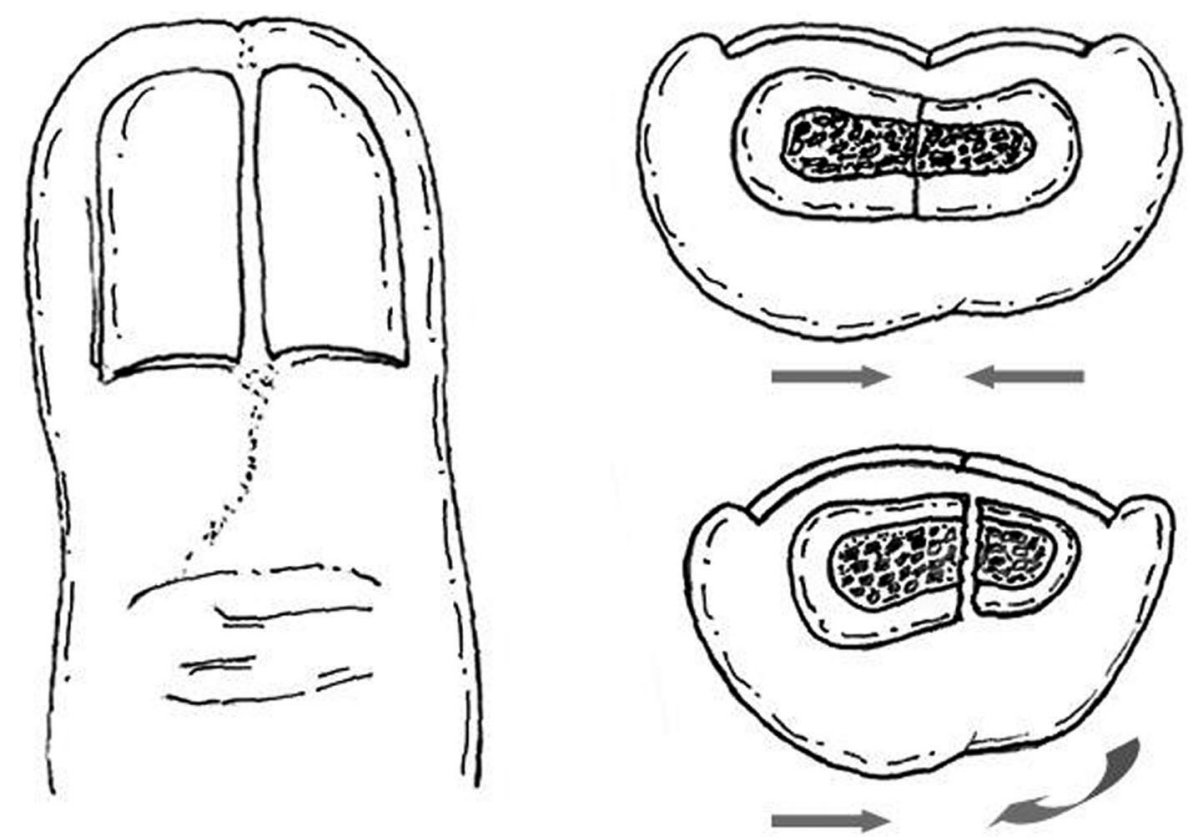

Fig. 2

Axial rotation of the distal phalangeal bone is necessary to make one semicircular nail bed (right bottom). Attaching two semicircular nails in a transverse plane creates a so-called seagull deformity (right top). 
The Journal of BOnE \& JoInt Surgery · JBJS.ORG Volume 89-A · Number 3 · MARCH 2007
Modified Bilhaut-Cloquet Procedure for Wassel Type-II AND III POLYDACTyly of The Thumb

\begin{tabular}{|c|c|c|c|c|}
\hline \multicolumn{2}{|c|}{$\begin{array}{c}\text { Angulation of } \\
\text { Interphalangeal Joint }\end{array}$} & \multirow{2}{*}{$\begin{array}{c}\text { Combined Phalangeal } \\
\text { Osteotomy }\end{array}$} & \multirow{2}{*}{$\begin{array}{c}\text { Time to Radiographic } \\
\text { Union (wk) }\end{array}$} & \multirow[b]{2}{*}{ Residual Angulation } \\
\hline Radial Digit & Ulnar Digit & & & \\
\hline $10^{\circ}$ of ulnar dev. & $10^{\circ}$ of radial dev. & None & 8 & $18^{\circ}$ of radial dev. \\
\hline $0^{\circ}$ & $0^{\circ}$ & None & 8 & 0 \\
\hline $10^{\circ}$ of ulnar dev. & $20^{\circ}$ of radial dev. & Yes & 4 & $5^{\circ}$ of radial dev. \\
\hline $0^{\circ}$ & $0^{\circ}$ & None & 12 & $5^{\circ}$ of ulnar dev. \\
\hline $10^{\circ}$ of ulnar dev. & $20^{\circ}$ of radial dev. & Yes & 52 & $5^{\circ}$ of radial dev. \\
\hline $20^{\circ}$ of radial dev. & $25^{\circ}$ of ulnar dev. & None & 6 & 0 \\
\hline $25^{\circ}$ of radial dev. & $20^{\circ}$ of ulnar dev. & None & 8 & $7^{\circ}$ of ulnar dev. \\
\hline
\end{tabular}

The patients were evaluated with respect to the function and appearance of the thumb by an independent examiner at an average follow-up period of fifty-two months (range, eighteen to seventy months). The size of the nail and the alignment, length, and circumference of the thumb were measured. To assess the function of the thumb, the range of motion and stability of the interphalangeal joint were tested. The joint was assessed as being unstable if there was $>10^{\circ}$ of varus or valgus angulation with stress. Bone-healing and any growth plate changes were evaluated radiographically. The overall satisfaction of the parents was determined by their selection of one of the following responses, indicating whether
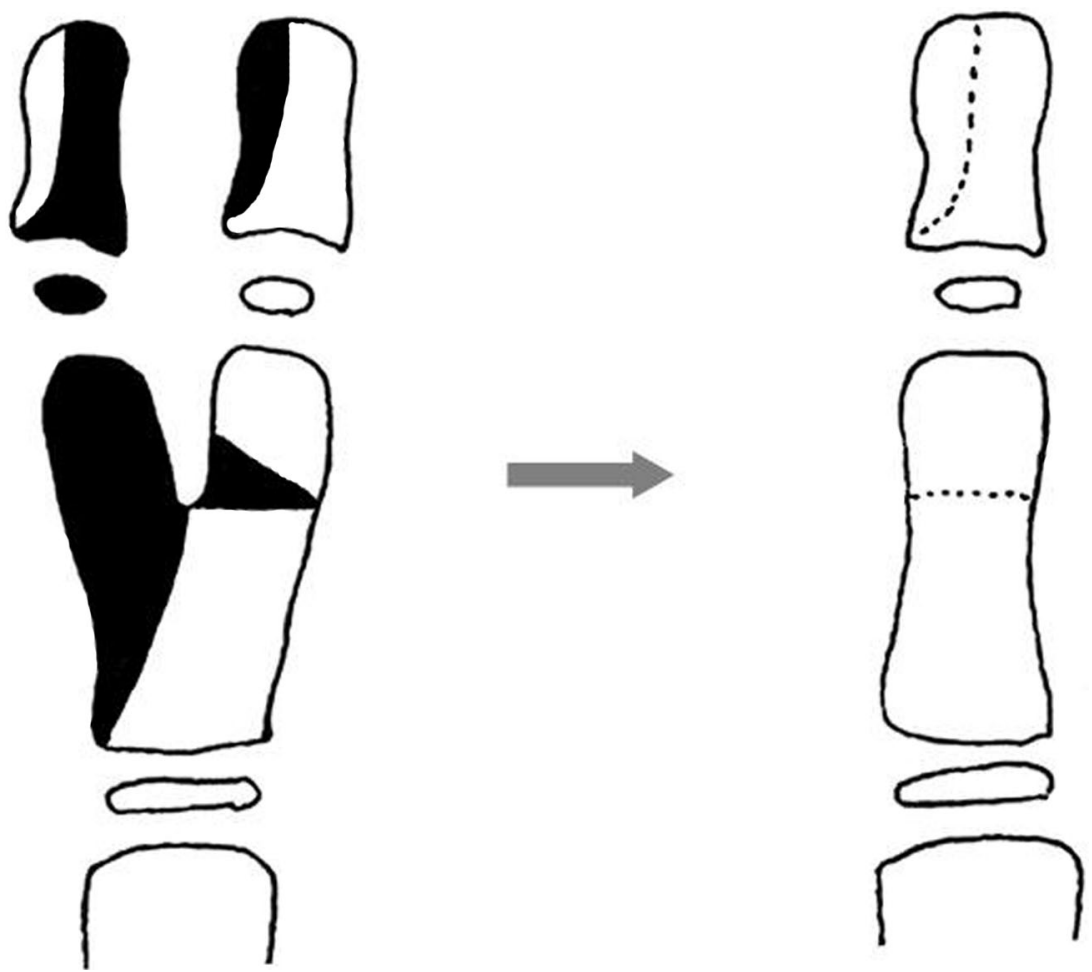

Fig. 3

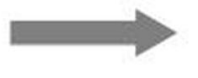

The modified Bilhaut-Cloquet procedure for a Wassel type-III bifid thumb. The dark area is resected, the two distal phalangeal bones are combined, and a corrective osteotomy of the proximal phalanx is performed. 
The Journal of Bone \& JoInt Surgery • JBJS.org VOLUme 89-A · Number 3 - MARCH 2007
Modified Bilhaut-Cloquet Procedure for Wassel Type-II AND III POLYDACTYLY OF THE THUMB

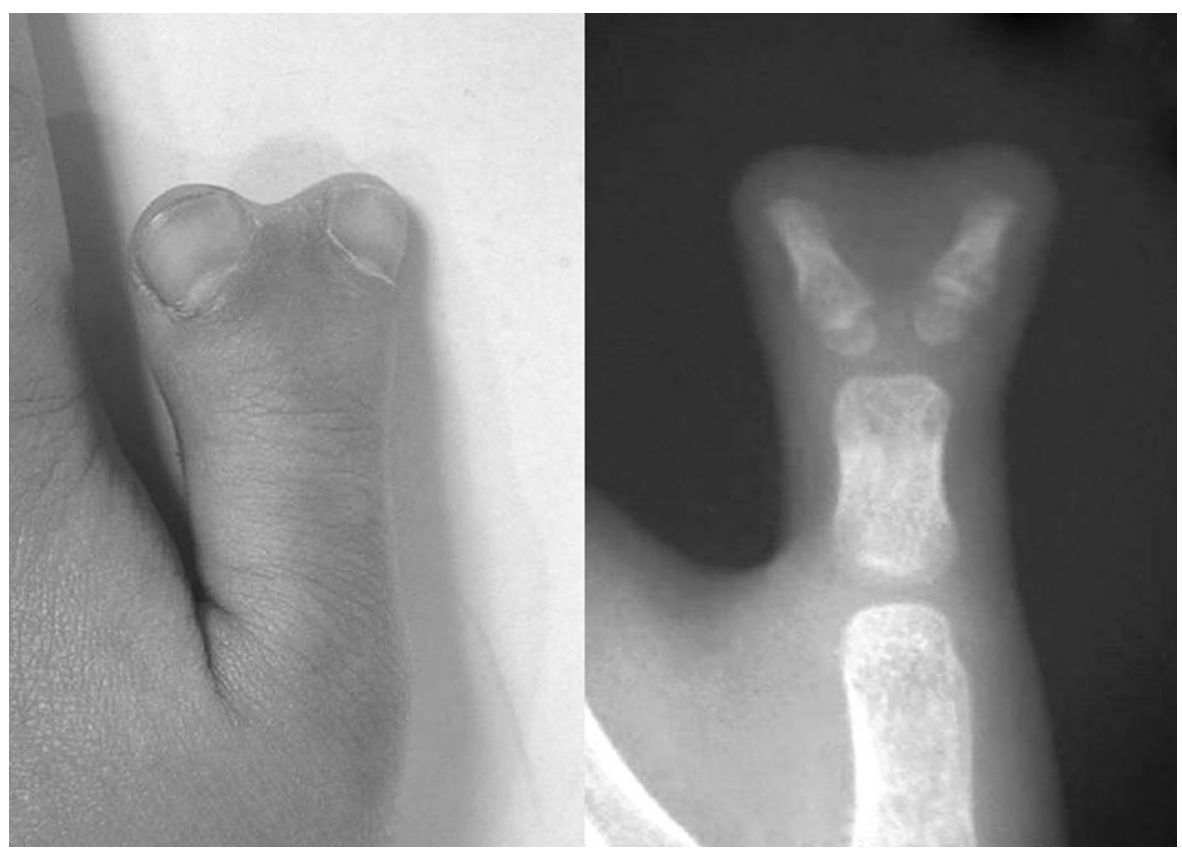

Fig. 4-A

Figs. 4-A through 4-E Case 6. A four-year-old boy with type-ll polydactyly of the left thumb.

Fig. 4-A Preoperative photograph (left) and anteroposterior radiograph (right).

they were "satisfied," "satisfied but with some reservation," or "dissatisfied." The parents were asked whether they would have their child undergo the same operation again. The overall satisfaction of the children was determined by their response to the question: "Is your thumb pretty?" or "Do you like it?" At the final follow-up evaluation, the mean age of the children was eighty-two months (range, fifty-five to 102 months).

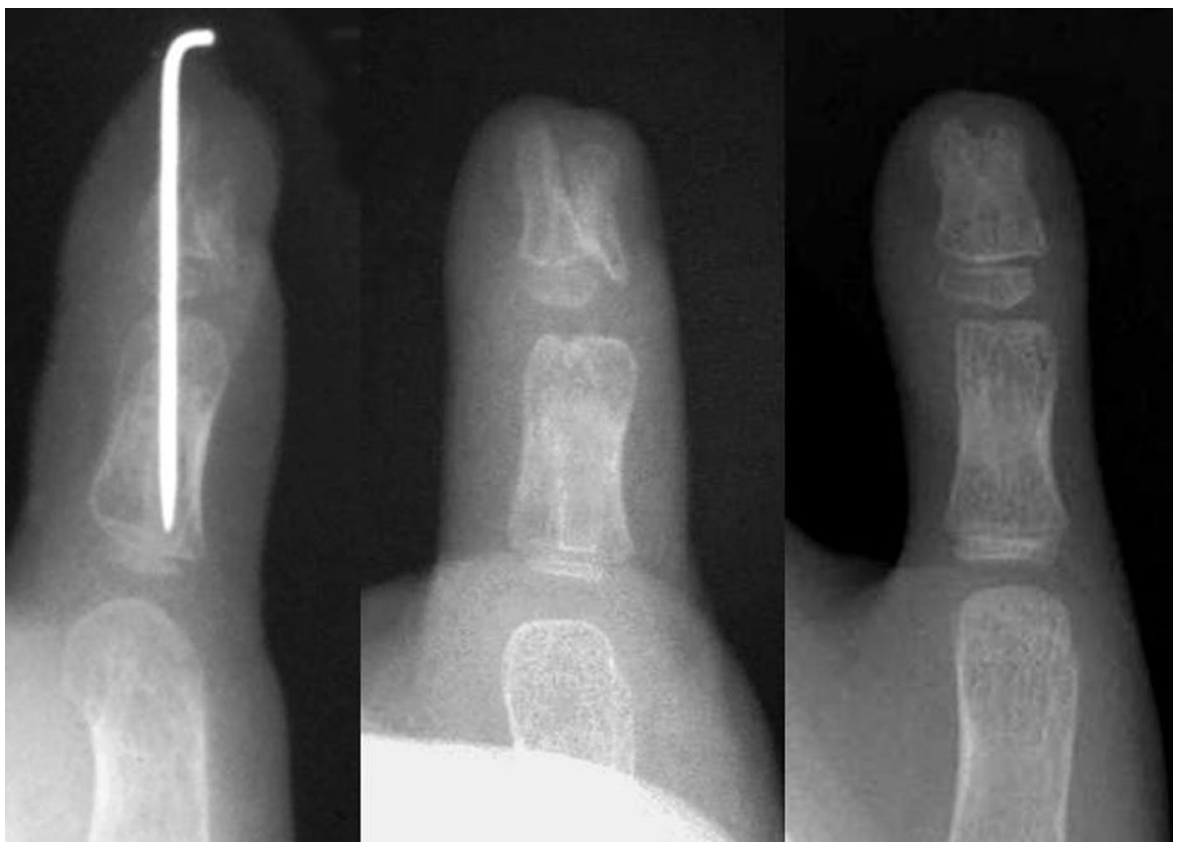

Fig. 4-B

Radiographs made immediately postoperatively (left), six weeks after surgery (middle), and eighteen months (right) after the modified Bilhaut-Cloquet procedure, showing remodeling of the distal phalanx with time. 
The Journal of Bone \& JOINT SURGERY • JBJS. ORG VOLUME 89-A · Number 3 · MARCH 2007

\section{Results}

Demographic data on the patients and the results of the functional evaluations are reported in Table I. All patients and their parents were satisfied with the cosmetic and functional results at the time of the final assessment. All parents said they would have their children undergo the same surgical procedure again.

The width of the nail in the combined thumb was nearly the same as that in the contralateral thumb. However, nail lengths were not similar when the initial nail lengths in the reconstructed thumb and the length discrepancy caused a stepoff of the lunula (Figs. 4-A through 4-E). No nail plate deformity or groove developed, and the longitudinal suture line of the nail became less prominent with time. Residual angular deformity was $<10^{\circ}$ in all patients except one (Case 1 ) with a

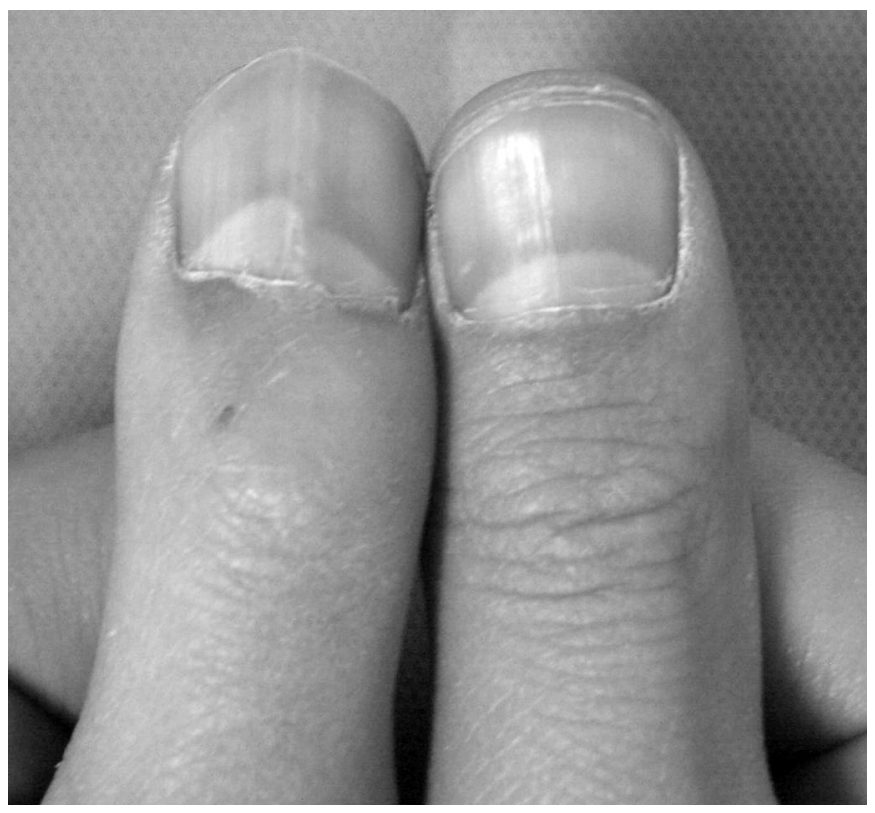

Fig. 4-C

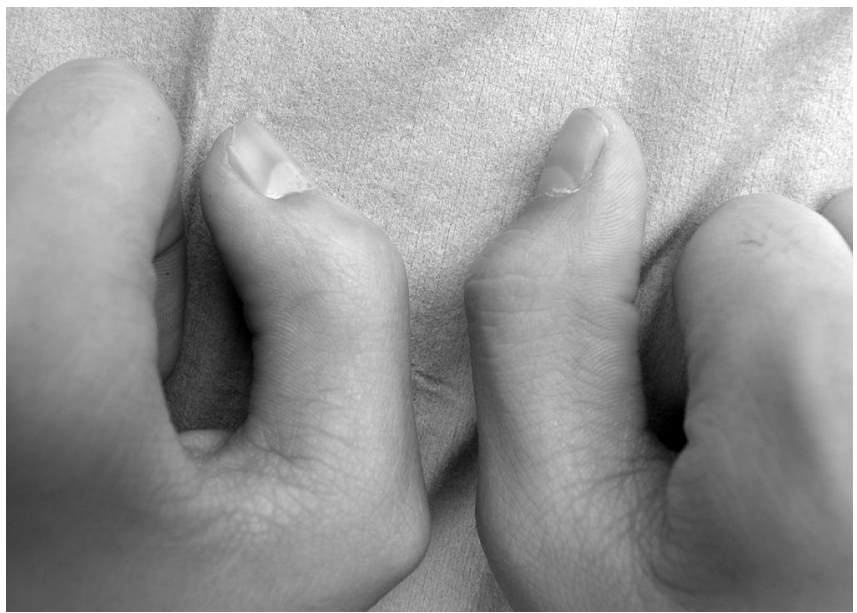

Fig. 4-D tour of the nail and the pulp (Fig. 4-E) at the latest follow-up examination at seventy months postoperatively.
Modified Bilhaut-Cloquet Procedure For Wassel Type-II AND III POLYDACTYly OF THE THUMB

type-III deformity (Figs. 5-A and 5-B) who gradually had an angular deviation deformity develop at the interphalangeal joint. At the time of the eighteen-month follow-up, the patient had $18^{\circ}$ of radial deviation, but the parents did not want additional surgery.

In patients with a type-III deformity, the postoperative range of motion of the interphalangeal joint averaged $57^{\circ}$ (range, $45^{\circ}$ to $90^{\circ}$ ). The two patients with a type-II deformity showed improved range of motion of the interphalangeal joint (from $20^{\circ}$ preoperatively to $45^{\circ}$ postoperatively in one and from $40^{\circ}$ to $60^{\circ}$ in the other). No patient had an unstable interphalangeal joint.

The time to solid osseous union of the distal phalangeal osteosynthesis radiographically ranged from four weeks to as much as a year; however, after removal of the transverse Kirschner wire at four to six weeks postoperatively, osseus healing was adequate for stability without pain. Remodeling of the distal phalanx occurred with time. At the latest follow-up evaluation, no evidence of physeal injury or growth arrest was observed in any patient.

\section{Discussion}

T nvestigators have reported both satisfactory and disappointing results for the Bilhaut-Cloquet operation, and some have modified the procedure. Hartrampf et al. ${ }^{10}$ adopted the standard Bilhaut-Cloquet procedure for more proximal duplications and achieved improved thumb alignment, but most of their patients ended up with a fused interphalangeal joint. Andrew and Sykes ${ }^{11}$ reported satisfactory results with the original technique, but they did not mention the interphalangeal joint motion. Naasan and Page ${ }^{12}$ found the procedure helpful in patients with type-III and IV polydactyly of the thumb, but secondary deformities were observed in $71 \%$ of their patients. Ganley and Lubahn $^{13}$ reported five patients with satisfactory results, but four had limited interphalangeal joint motion.

As a modification of this procedure, Miura ${ }^{2}$ removed the

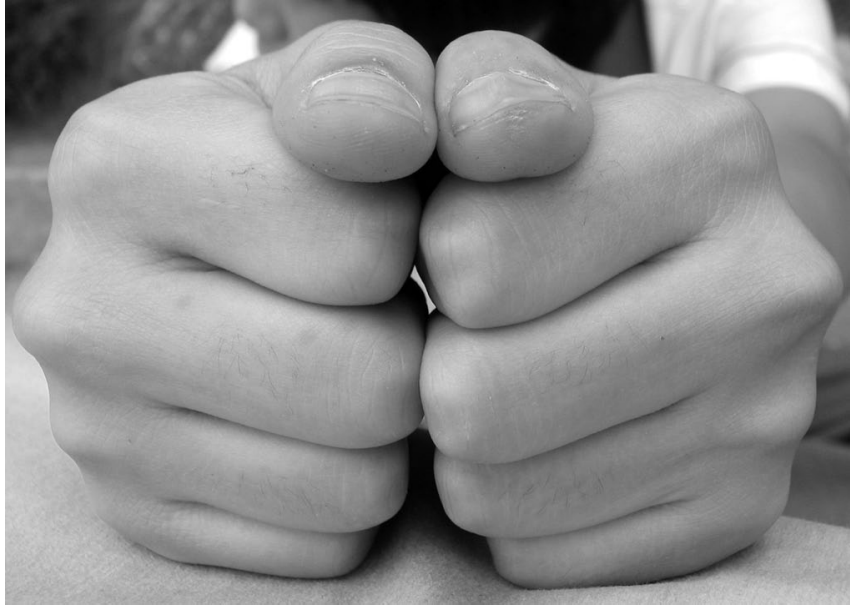

Fig. 4-E 
The JOURnAL OF BONE \& JOINT SURGERY • JBIS. ORG Volume 89-A · Number 3 · MARCH 2007
Modified Bilhaut-Cloquet Procedure for Wassel Type-II AND III POLydactyly of The Thumb nail and bone from the extra thumb and used only the remaining soft parts to reconstruct the thumb. Similarly, Simmons ${ }^{14}$ treated type-II duplication by ablating the radial digit and reconstructing the radial perionychium from the radial soft-tissue flap, and Cheng et al. ${ }^{4}$ modified this approach by resecting the osseous appendages of the thumb while retaining the soft tissue and a part of the nail. However, the above modifications with use of only the soft part of the excised thumb cannot produce a

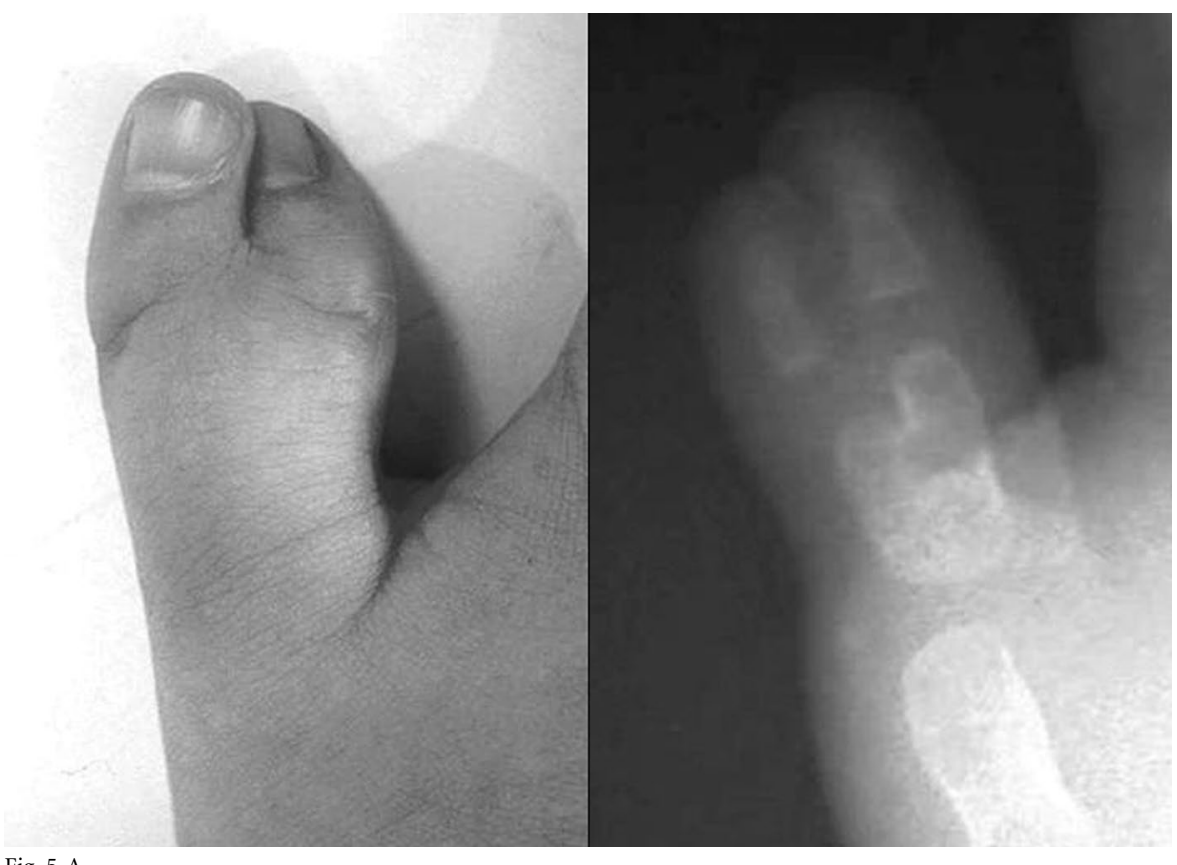

Fig. 5-A

Figs. 5-A and 5-B Case 1. A two-year-old girl with type-Ill polydactyly of the right thumb. Fig. 5-A Preoperative photograph (left) and anteroposterior radiograph (right) of the thumb.

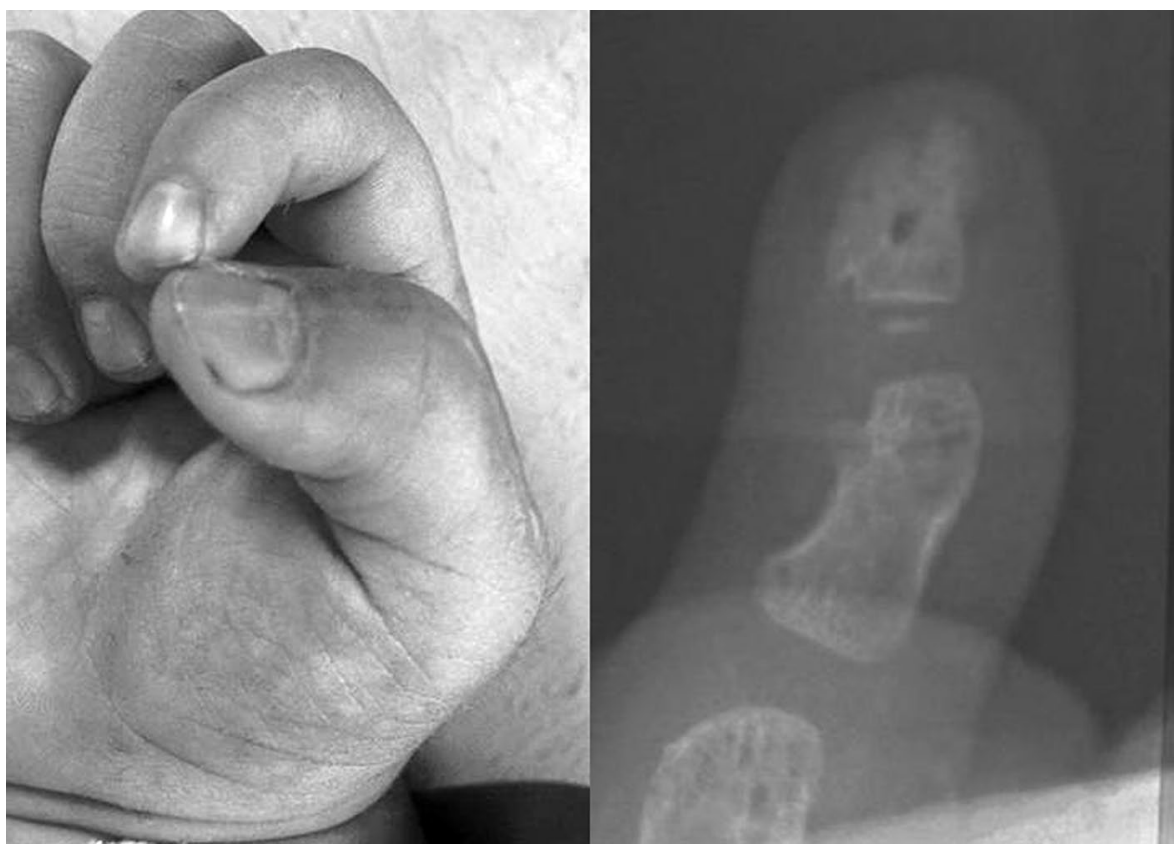

Fig. 5-B

Photograph (left), made eighteen months after the modified Bilhaut-Cloquet procedure, showed good flexion of the interphalangeal joint, although the anteroposterior radiograph (right) demonstrated some persistent angular deformity. 
The Journal of Bone \& JOINT SURGERY · JBIS.ORG Volume 89-A · Number 3 - MARCH 2007
Modified Bilhaut-Cloquet Procedure for Wassel Type-II AND III POLYdaCtyly of The Thumb nail that is stable and large enough. Ogino et al. ${ }^{15}$ treated four patients using their modified procedure, in which the periosteum and a minimum amount of bone were removed from the adjacent sides in order to minimize damage to the growth plates and articular surfaces; however, the final postoperative joint motion was not reported.

In our series, the postoperative interphalangeal joint motion was preserved in type-III deformities and improved in type-II deformities. We believe this was because we used an extra-articular technique. Additionally, no patient had a nail deformity develop and the longitudinal line of the sutured nail bed became less prominent with time. The natural axial curvature of a nail is semicircular; therefore, attaching two semicircular nails in a transverse plane alone can create a so-called seagull deformity (Fig. 2). To prevent this, the phalangeal bone supporting the nail bed requires slight axial rotation, and at the same time the nail bed is repaired with more tension than by simple approximation. If the articular surfaces are to be combined as in the classic method, there should be no gap between them to ensure a smooth articulating surface. This technique provides the phalangeal bone with less mobility for achieving this small amount of rotation or for optimal tensioning of the nail bed. In our modified technique, no attempt was made to compress the distal phalangeal bones, thus facilitating easy adjustment and contouring of the combined nail bed. This concept of osteosynthesis did not cause any problem during the healing process, ultimately resulting in osseous healing and remodeling of the distal phalanx.

The limitation of this technique is that, as in the original method, it is not possible to make a thumb with the same nail length as the normal side when the initial nail lengths of the duplicated thumb differ from that of the normal thumb. Although trimming of the nail plates can make this nail length discrepancy less prominent, a step-off of the lunula is unavoidable in some cases. Angular deformity of the interpha- langeal joint developed gradually in one of our patients with type-III polydactyly. Eccentric insertions of the flexor pollicis longus and/or extensor pollicis longus are common in patients in whom the interphalangeal joints are angulated preoperatively ${ }^{5}$. Therefore, the flexor and extensor tendon insertions should be carefully examined, and tendon realignment should be performed if necessary ${ }^{6}$.

Dobyns et al. ${ }^{5}$ indicated that the retained thumb should be at least $80 \%$ of the size of the contralateral thumb, and, if not, it should be augmented by some combining method. Our indication for the combining procedure was when the size of the nail was less than two-thirds of that of the contralateral nail or less than the size of the index fingernail in patients with bilateral involvement. It is our experience that if a hypoplastic thumb is removed at an earlier age and the patient can use the reconstructed thumb functionally, the thumb usually grows quickly by so-called catch-up growth ${ }^{16}$.

We agree with Manske ${ }^{17}$ that a well-formed smaller thumb can be functionally and cosmetically acceptable. In selected patients in whom combining thumbs is desirable, our modified Bilhaut-Cloquet procedure is effective in preserving interphalangeal joint motion, minimizing nail deformity, and preventing growth arrest.

Goo Hyun Baek, MD

Hyun Sik Gong, MD

Moon Sang Chung, MD

Joo Han Oh, MD

Young Ho Lee, MD

Sang Ki Lee, MD

Department of Orthopedic Surgery, Seoul National University College of Medicine, 28 Yongon-dong, Chongno-gu, Seoul 110-744, South Korea.

E-mail address for G.H. Baek: ghbaek@snu.ac.kr

doi:10.2106/JBJS.F.00812

\section{References}

1. Wassel HD. The results of surgery for polydactyly of the thumb: a review. Clin Orthop Relat Res. 1969;64:175-93.

2. Miura T. Duplicated thumb. Plast Reconstr Surg. 1982;69:470-81.

3. Tada K, Yonenobu K, Tsuyuguchi Y, Kawai H, Egawa T. Duplication of the thumb. A retrospective review of two hundred and thirty-seven cases. J Bone Joint Surg Am. 1983;65:584-98.

4. Cheng JC, Chan KM, Ma GF, Leung PC. Polydactyly of the thumb: a surgical plan based on ninety-five cases. J Hand Surg [Am]. 1984;9:155-64.

5. Dobyns JH, Lipscomb PR, Cooney WP Management of thumb duplication. Clin Orthop Relat Res. 1985;195:26-44.

6. Cohen MS. Thumb duplication. Hand Clin. 1998;14:17-27.

7. Bilhaut M. Guerison d'un pouce bifide par un nouveau procede operatoire. Congr Fr Chir. 1890;4:576-80.

8. Marks TW, Bayne LG. Polydactyly of the thumb: abnormal anatomy and treatment. J Hand Surg [Am]. 1978;3:107-16.

9. Townsend DJ, Lipp EB Jr, Chun K, Reinker K, Tuch B. Thumb duplication, 66 years' experience-a review of surgical complications. J Hand
Surg [Am]. 1994;19:973-6.

10. Hartrampf CR, Vasconez LO, Mathes S. Construction of one good thumb from both parts of a congenitally bifid thumb. Plast Reconstr Surg. 1974;54:148-52.

11. Andrew JG, Sykes PJ. Duplicate thumbs: a survey of results in twenty patients. J Hand Surg [Br]. 1988;13:50-3.

12. Naasan A, Page RE. Duplication of the thumb. A 20-year retrospective review. J Hand Surg [Br]. 1994;19:355-60.

13. Ganley TJ, Lubahn JD. Radial polydactyly: an outcome study. Ann Plast Surg. 1995;35:86-9.

14. Simmons BP. Polydactyly. Hand Clin. 1985;1:545-65.

15. Ogino $\mathrm{T}$, Ishii $\mathrm{S}$, Takahata $\mathrm{S}$, Kato $\mathrm{H}$. Long-term results of surgical treatment of thumb polydactyly. J Hand Surg [Am]. 1996;21:478-86.

16. Gafni RI, Baron J. Catch-up growth: possible mechanisms. Pediatr Nephrol. 2000;14:616-9.

17. Manske PR. Treatment of duplicated thumb using a ligamentous/periosteal flap. J Hand Surg [Am]. 1989;14:728-33. 